\title{
Hot tearing behavior of NZ30K Mg alloy under progressive solidification
}

\author{
Ke Wang', *Peng-huai Fu', 2 , Li-ming Peng', Ying-xin Wang', Wen-jiang Ding' \\ 1. National Engineering Research Center of Light Alloy Net Forming and State Key Laboratory of Metal Matrix Composites, \\ Shanghai Jiao Tong University, Shanghai 200240, China \\ 2. Shanghai Light Alloy Net Forming National Engineering Research Center Co., Ltd., Shanghai 201615, China
}

\begin{abstract}
Progressive solidification is usually considered an effective strategy to reduce the hot tearing susceptibility of a cast component. In this study, special constrained plate castings with progressive changes in cross-section were designed, which enabled progressive solidification. The hot tearing behavior of a newly developed NZ3OK Mg alloy (Mg-3.0Nd-0.2Zn-Zr, wt.\%) was studied under progressive solidification using various mold temperature distributions and constraint lengths. Of these, a homogeneous mold temperature distribution is found to be the best option to avoid hot tearing, followed by a local low mold temperature distribution (with a chiller), then a gradient mold temperature distribution. Unexpectedly, compared with the homogeneous mold temperature distribution, adding a chiller does not provide any further reduction in the hot tearing susceptibility of the NZ30K Mg alloy. A high mold temperature and a short constraint length increase the hot tearing resistance of cast Mg alloys. Progressive solidification is not a sufficient and necessary condition to avoid the formation of hot tearing. The two key factors that determine the occurrence of hot tearing under progressive solidification are the maximum cooling rate and the constraint length. Decreasing these values can reduce the incidence of hot tearing.
\end{abstract}

Key words: hot tearing; progressive solidification; cooling rate; constraint length; Mg alloy

CLC numbers: TG146.22 Document code: A Article ID: 1672-6421(2021)01-029-08

\section{Introduction}

Magnesium ( $\mathrm{Mg})$ alloys have recently attracted increasing interest for industrial applications because of their high specific strength and excellent functional performance ${ }^{[1-3]}$. However, hot tearing, a fatal defect that frequently occurs during the casting of $\mathrm{Mg}$ components, is an obstacle to the widespread application of $\mathrm{Mg}$ alloys. Thus, there is an urgent need to prevent the hot tearing of $\mathrm{Mg}$ alloys.

Many factors affect the hot tearing of a particular $\mathrm{Mg}$ component. Mainly, these are alloy composition, casting condition, and geometry of the casting mold. Most studies have focused on the effects of alloy compositions and casting conditions. The effect of alloy compositions on the hot tearing susceptibility (HTS) has been extensively studied for binary $\mathrm{Mg}$ alloys (e.g., $\mathrm{Mg}-\mathrm{Al}{ }^{[4]}, \mathrm{Mg}-\mathrm{Zn}^{[5]}$,

\section{*Peng-huai Fu}

Male, Associate Researcher, earned his Ph.D degree at Shanghai Jiao Tong University in 2009. He is now doing research on Mg/Al alloys, casting \& additive manufacturing at Shanghai Jiao Tong University.

E-mail: fph112sjtu@sjtu.edu.cn;

Received: 2020-05-13; Accepted: 2020-10-21
$\mathrm{Mg}-\mathrm{Ca}^{[6]}$, and Mg-rare earth $\left.{ }^{[7]}\right)$ and ternary $\mathrm{Mg}$ alloys (e.g., $\mathrm{Mg}-\mathrm{Al}-\mathrm{Zn}{ }^{[8,9]}, \mathrm{Mg}-\mathrm{Al}-\mathrm{Ca}{ }^{[10]}, \mathrm{Mg}-\mathrm{Al}-\mathrm{Sr}^{[11]}$, and $\left.\mathrm{Mg}-\mathrm{Zn}-\mathrm{Ca}{ }^{[12]}\right)$. The HTS of most binary alloys follows a lambda $(\lambda)$ curve, whereas the ternary alloys only exhibit maximum HTS at a certain composition ${ }^{[3]}$. Casting conditions mainly refer to pouring temperature and mold temperature for Mg alloys. Most studies have shown that pouring temperature has a limited effect on HTS compared with mold temperature ${ }^{[13]}$. Nearly all of the previous studies have shown that a high mold temperature significantly increases the hot tearing resistance of $\mathrm{Mg}$ alloys. For example, a study of $\mathrm{Mg}$ $2 \mathrm{Ca}-x \mathrm{Zn}$ (wt.\%) alloys clearly indicated that the HTS decreased dramatically when the mold temperature increased from $250{ }^{\circ} \mathrm{C}$ to $450{ }^{\circ} \mathrm{C}{ }^{[12]}$.

For a particular $\mathrm{Mg}$ component with a fixed alloy composition, mold design and casting conditions are two important factors that can be controlled to avoid hot tearing. To the mold design, progressive solidification is believed to be an effective strategy to reduce the HTS of a cast component and it is frequently used in practice. Directional and progressive solidification with favorable thermal gradients have been reported to overcome multiple phenomena, including hot tearing, 
centerline porosity, and macro-segregation, in a large wedgeshaped steel casting ${ }^{[14]}$. However, similar research on the effect of progressive solidification in $\mathrm{Mg}$ alloys is quite limited in available literature, and further experimental evidence is needed to confirm whether a progressive solidification strategy can be used to increase the hot tearing resistance of $\mathrm{Mg}$ alloys. Thus, in this study, new constrained plate castings (CPCs) with progressive changes in the cross-section were designed to enable progressive solidification, and the hot tearing behaviors of a newly developed NZ30K (Mg-3Nd-0.2Zn-Zr, wt.\%) Mg alloy ${ }^{[15,16]}$ were studied.

\section{Experimental and simulation methods}

\subsection{Experimental procedure}

A newly developed NZ30K Mg alloy (Mg-3Nd-0.2Zn-Zr, wt.\%) ${ }^{[15-18]}$ was prepared using high-purity $\mathrm{Mg}$ and $\mathrm{Zn}, \mathrm{Mg}$ $25 \% \mathrm{Nd}$ and $\mathrm{Mg}-30 \% \mathrm{Zr}$ master alloys, and melted in an electrical-resistance furnace under the protection of a gas mixture of $\mathrm{CO}_{2}+\mathrm{SF}_{6}$. The metal was refined with JDMJ refining flux $\left(45 \% \mathrm{MgCl}_{2}, 25 \% \mathrm{KCl}, 20 \% \mathrm{NaCl}, 10 \% \mathrm{CaCO}_{3}\right.$, mass fraction) at $760-780{ }^{\circ} \mathrm{C}$ and then held at that temperature for approximately $20 \mathrm{~min}$ before casting ${ }^{[13]}$. The pouring temperature was fixed at $740{ }^{\circ} \mathrm{C}$.

Figure 1 presents a schematic illustration of the CPCs and their molds. The widths of the plates were designed to gradually change to ensure that solidification occurred gradually, which differed from the constant cross-section of conventionally used constrained rod castings ${ }^{[4,11,19,20]}$. A riser was placed above the sprue to feed the plates. Dual plates were designed to increase test efficiency. Three different CPCs (CPC1, CPC2, and CPC3) were used, as shown in Figs. 1(a)-(c). Figures 1(d)-(g) present the assembly diagram and exploded view of the mold. The mold was made of H13 steel (ASTM, USA) and consisted of the following parts:

(1) Pouring cup [No. 1, Fig. 1(d)] divided into two half parts;

(2) Cover plate [Nos. 2-4, Figs. 1(d)-(e)] divided into three parts (A, B, and C);

(3) Bottom mold [No. 5, Figs. 1(d)-(e)] with casting cavity;

(4) Electric heating pipes [No. 6, Figs. 1(d)-(e)] used to heat the mold;

(5) Removable inserts [Nos. 7-14, Inserts 1-8, Figs. 1(e)(g)] used to replace the mold with different shapes and make different constrained plates;

(6) Thermocouples [TC1-TC4, type K, Fig. 1(e)] inserted into the holes in the bottom mold. TC1 is used to control the mold temperature and TC2-TC4 are used to monitor the mold temperature. The temperatures of TC1-TC4 before pouring are used as the initial mold temperatures in the simulation.

CPC1 [Fig. 1(a)] constrained by the sprue and the flange (the constraint end) was used to investigate the effect of mold temperature on the formation of hot tearing. The corresponding mold is shown in Fig. 1(e). To investigate the effect of the temperature distribution on hot tearing, three different mold heating strategies were used for $\mathrm{CPC} 1$.

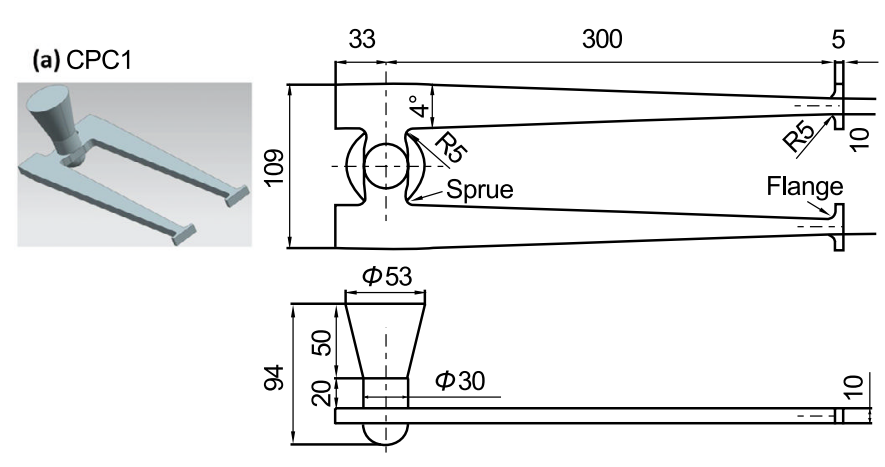

(b) $\mathrm{CPC} 2$

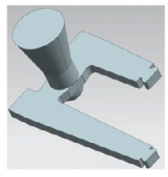

(c) $\mathrm{CPC} 3$

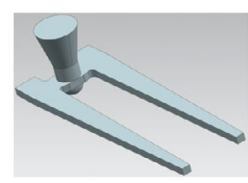

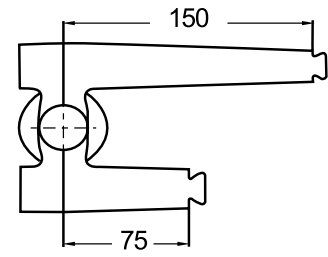

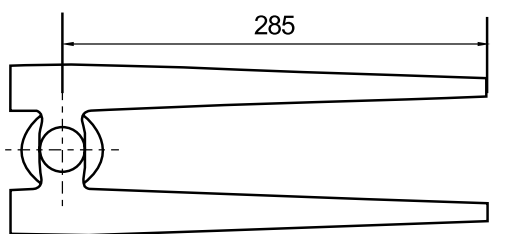

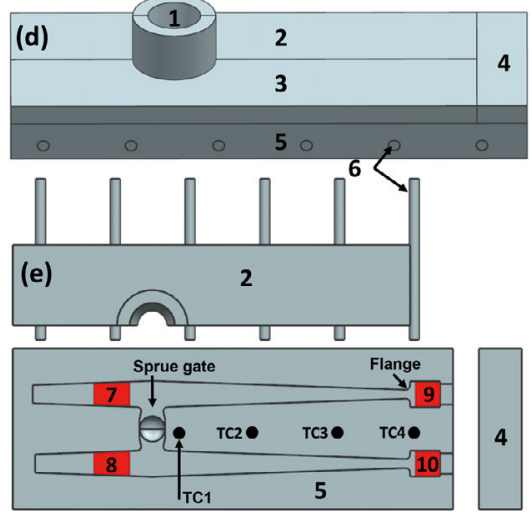

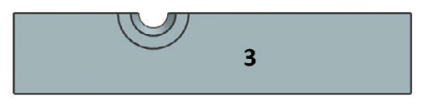

1 Pouring cup

2 Cover plate $\mathrm{A}$ 3 Cover plate $B$

(f)

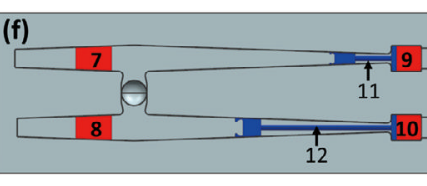

4 Cover plate $C$

5 Bottom mold

6 Electric heating pipe

7 Insert 1

8 Insert 2

9 Insert 3

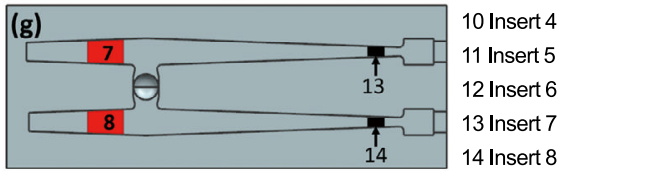

Fig. 1: Schematic diagram of constrained plate castings (CPCs) and their molds: (a) CPC1; (b) CPC2; (c) CPC3; (d) assembly diagram of mold; (e) exploded view of CPC1 mold, showing positions of thermocouples and insert of CPC1 in bottom mold; (f) bottom mold of CPC2; (g) bottom mold of CPC3 (unit: $\mathrm{mm}$ ) 
The first strategy is a homogeneous mold temperature distribution (HT). To obtain a homogeneous mold temperature field, the mold was completely wrapped by asbestos during the mold heating process, and held at the set temperature for $30 \mathrm{~min}$ before pouring. In this case, the temperature value of TC1 could be treated as the temperature of the entire mold.

The second strategy is a local low mold temperature distribution (LLT). Cover plate $\mathrm{C}$ was removed during the mold heating process and then quickly moved back to cover plate $\mathrm{C}$ before pouring. The mold heating process is the same as HT before pouring. During solidification, cover plate $\mathrm{C}$ acted as a chiller because of its low temperature (room temperature, about $25^{\circ} \mathrm{C}$ ). In this case, the temperature of TC1 could be treated as the temperature of the entire mold, with the exception of cover plate $\mathrm{C}$.

The third strategy is a gradient mold temperature distribution (GT). The last two electric heating pipes at the right end of the bottom mold were removed during the mold heating process. When the temperature of $\mathrm{TC} 1$ reached the set temperature, the molten metal was poured into the mold cavity. In this case, the mold temperature gradually decreased from the sprue to the constrained end, and the temperature of TC1 could be treated as the mold temperature near the sprue.

CPC2 [Fig. 1(b)], which was also constrained by the sprue and the constraint end, was used to investigate the effect of constraint length on the formation of hot tearing. The corresponding mold is shown in Fig. 1(f). CPC3 [Fig. 1(c)], which was only constrained by the sprue, was used to investigate the effect of constraint on the formation of hot tearing. The corresponding mold is shown in Fig. 1(g). Because there was only one constraint point (sprue), CPC3 could shrink freely during solidification. The molds of CPC 2 and CPC 3 were prepared by adding removable inserts (Inserts 5-8) into the bottom mold of CPC1. The HT mold heating strategy was used for CPC2 and CPC3.

The experimental mold temperatures for the different CPCs used in this study are tabulated in Table 1. The castings were photographed after cover plates A-C [shown in Fig. 1(d)] were removed when the temperature at $\mathrm{TC} 1$ dropped to $100{ }^{\circ} \mathrm{C}$.

Table 1: Experimental mold temperatures of CPCs

\begin{tabular}{|c|c|c|}
\hline Casting & $\begin{array}{l}\text { Mold temperature } \\
\text { distribution strategy }\end{array}$ & Temperature at $\mathrm{TC} 1\left({ }^{\circ} \mathrm{C}\right)$ \\
\hline \multirow{7}{*}{ CPC1 } & HT & $350,400,450,475,500$ \\
\hline & LLT & $350,400,450,500,525,550$ \\
\hline & & 350 (TC1-TC4, 350-345-300-195) \\
\hline & & 400 (TC1-TC4, 400-362-322-260) \\
\hline & GT & 450 (TC1-TC4, 450-401-353-320) \\
\hline & & 500 (TC1-TC4, 500-443-375-325) \\
\hline & & 550 (TC1-TC4, 550-514-405-341) \\
\hline CPC2 & $\mathrm{HT}$ & $100,150,200,250,275,300,350$ \\
\hline СРC3 & HT & $150,250,350,450$ \\
\hline
\end{tabular}

\subsection{Numerical simulation}

Casting simulation software ProCAST (Universal Energy Systems, USA) was used to simulate the solidification time and cooling rate of the NZ30K alloy in the different casting processes. The simplified constrained plate castings and molds are shown in Fig. 2. The finite-element mesh was automatically generated by the software. The thermodynamic properties of the NZ30K alloy ${ }^{[15,16]}$ were calculated using the Thermodynamic Databases function embedded in the software, and the Scheil model was selected. Cooling rates were automatically calculated by the software as a linear interpolation of two temperatures ${ }^{[21]}$. Dahle et al. ${ }^{[22]}$ observed that the strength of an alloy started from a solid fraction $f_{\mathrm{s}}=0.74$ and then increased significantly with further solidification. Therefore, in this study, the temperature range $\left(623-529{ }^{\circ} \mathrm{C}\right)$ (a)

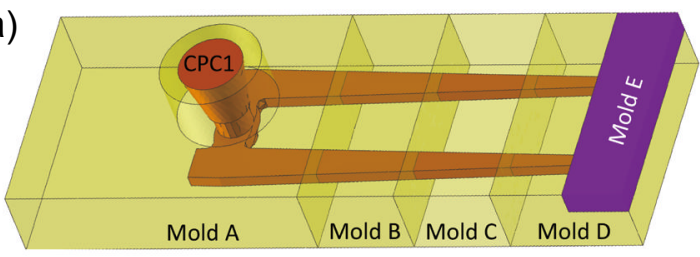

(b)

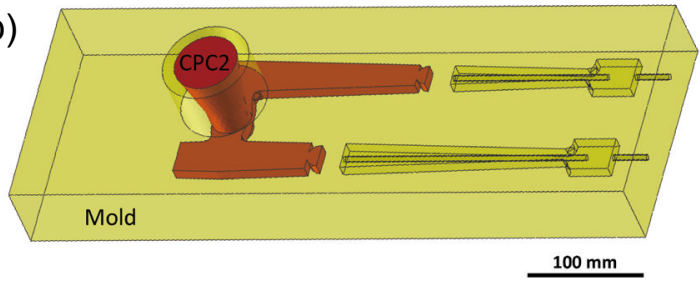

Fig. 2: Simplified molds of constrained plate castings used in simulation: (a) CPC1; (b) CPC2 
corresponding to solid fraction $f_{\mathrm{s}}=0.74$ to 1 was selected as the relative temperature range to calculate cooling rates. Figure 3 shows the representative nodes where cooling rates were calculated for CPC1 [Fig. 3(a)] and CPC2 [Fig. 3(b)]. During simulation of the filling and solidification processes, except for pouring temperature $\left(740{ }^{\circ} \mathrm{C}\right)$, mold temperature, and filling speed $\left(0.4 \mathrm{~m} \cdot \mathrm{s}^{-1}\right)$, default values were used for all other parameters. Simulated initial mold temperatures are shown in Table 2. Initial temperatures of Molds A, B, C, D, and $\mathrm{E}$ were set according to the experimental values in Table 1. In HT-475, TC1 was used as the temperature of Molds A-E. In LLT-475 and LLT-550, TC1 was used as the temperature of Molds A-D, and $25{ }^{\circ} \mathrm{C}$ (room temperature) was used as the temperature of Mold E. In GT-550, TC1, TC2, TC3, TC4, and TC4 were used as the temperatures of Molds A-E, respectively.
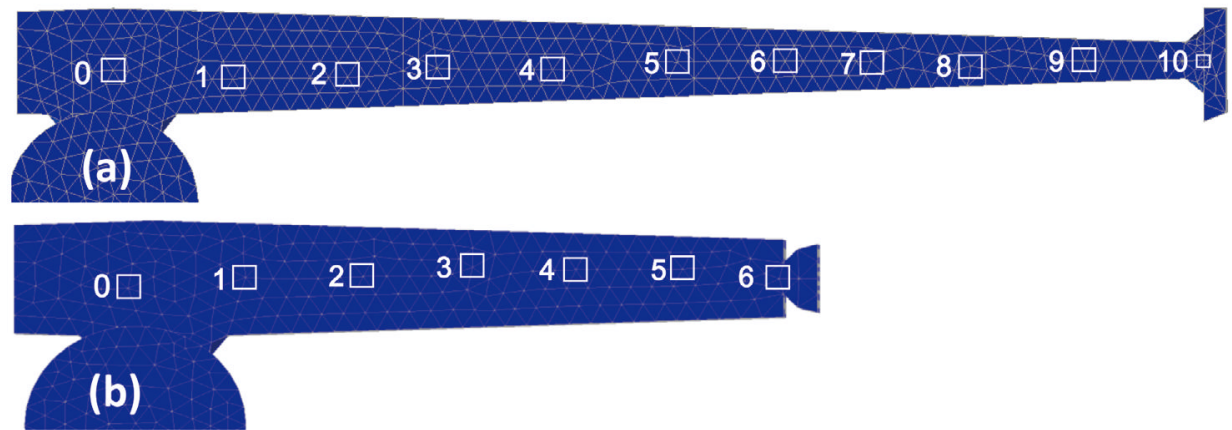

Fig. 3: Finite-element mesh and representative nodes used to calculate cooling rates: (a) CPC1; (b) CPC2. Nodes $0-10$ in Fig. 3(a) correspond to Positions 0-10 in Figs. 7 and 8 and Nodes 0-6 in Fig. 3(b) correspond to Positions 0-6 in Fig. 11

Table 2: Simulated initial mold temperatures

\begin{tabular}{rrrccc} 
Case & \multicolumn{3}{c}{ Mold temperature $\left({ }^{\circ} \mathrm{C}\right)$} \\
\hline HT-475 & Mold A & Mold B & Mold C & Mold D & Mold E \\
\hline LLT-475 & 475 & 475 & 475 & 475 & 475 \\
LLT-550 & 475 & 475 & 475 & 475 & 25 \\
GT-550 & 550 & 550 & 550 & 550 & 25 \\
& 550 & 514 & 405 & 341 & 341
\end{tabular}

\section{Results}

\subsection{Progressive solidification of constrained plate casting}

Figure 4 shows the solidification time of the constrained plate casting (CPC1) under HT-350 conditions. It is clear that CPC1 gradually solidified from the constrained end to the sprue, which indicates a typical progressive or directional solidification. Similar progressive solidification also occurred in $\mathrm{CPC} 2$ and $\mathrm{CPC} 3$.

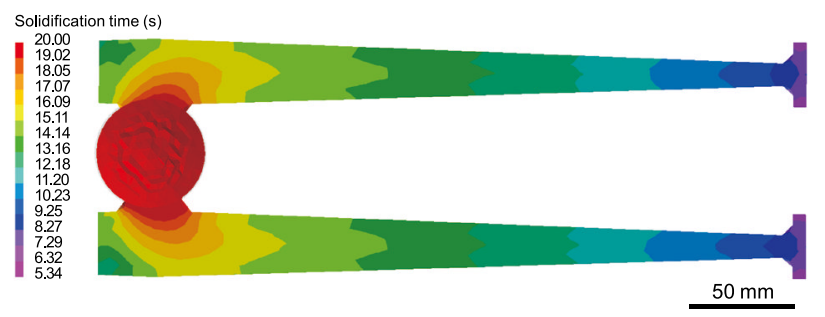

Fig. 4: Solidification sequence of $\mathrm{CPC} 1$ at pouring temperature of $740{ }^{\circ} \mathrm{C}$ and mold temperature of $350^{\circ} \mathrm{C}$ under $\mathrm{HT}$ distribution

\subsection{Effect of mold temperature}

Figure 5 presents representative images of $\mathrm{CPC} 1$ under the LLT distribution, and hot tearing are indicated by the arrows. With increasing mold temperature, the widths of the hot tearing gradually decrease, and the hot tearing finally disappeares when the mold temperature reaches $550{ }^{\circ} \mathrm{C}$. The hot tearing is perpendicular to the contraction direction (along the plates) and their locations are not fixed, which differs from observations for other constrained rod castings with fixed crack locations ${ }^{[4,19,20]}$

Figure 6 shows that the hot tearing occurrences of CPC1 under different mold temperature distributions. Under the HT distribution, hot tearing appears when the mold temperature is $450{ }^{\circ} \mathrm{C}$ or lower, and disappears at mold temperatures of $475{ }^{\circ} \mathrm{C}$ or higher. Under the LLT distribution, the hot tearing disappears only when the mold temperature reaches $550{ }^{\circ} \mathrm{C}$. Under the GT distribution, hot tearing is still observed even if the mold temperature reaches $550{ }^{\circ} \mathrm{C}$. Therefore, based on the temperature needed to eliminate hot tearing, the HT distribution is least likely to produce hot tearing, followed by the LLT 
distribution, whereas the GT distribution is most likely to cause hot tearing.

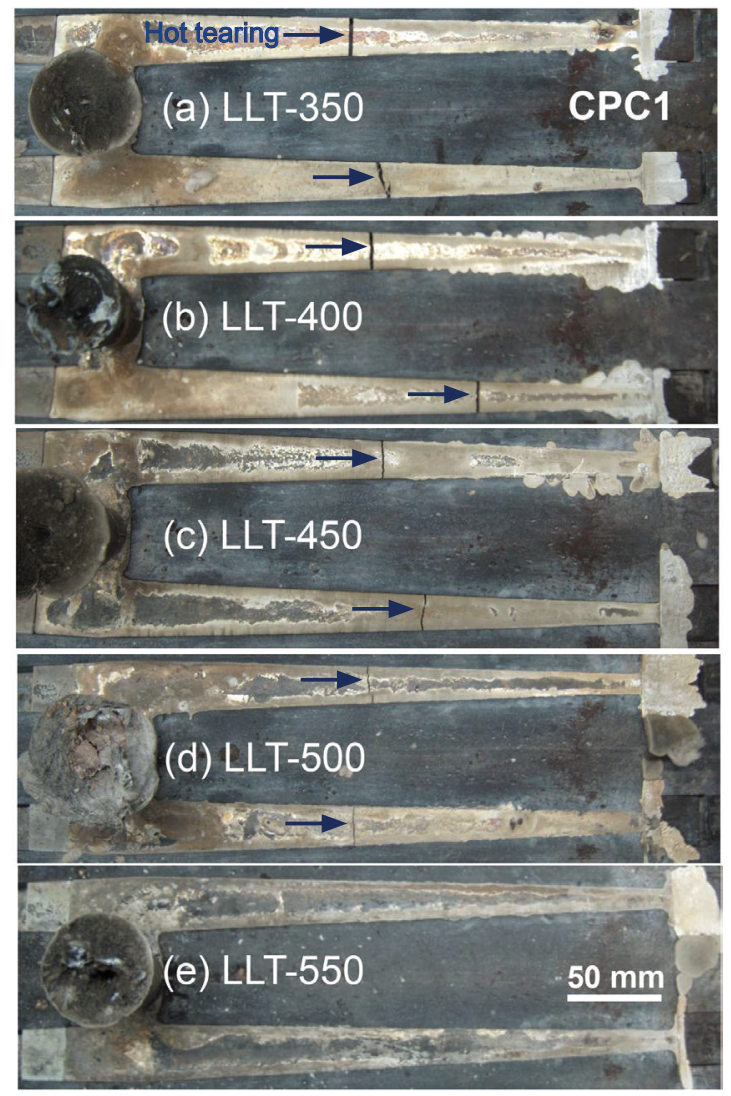

Fig. 5: Representative images of CPC1 under LLT distribution: (a) $350{ }^{\circ} \mathrm{C}$; (b) $400{ }^{\circ} \mathrm{C}$; (c) $450{ }^{\circ} \mathrm{C}$; (d) $500{ }^{\circ} \mathrm{C}$; (e) $550^{\circ} \mathrm{C}$

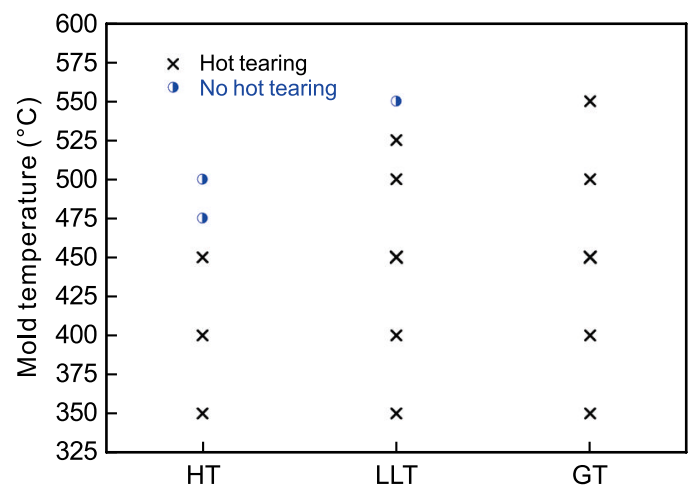

Fig. 6: Appearances of hot tearing of CPC1 under different mold temperature distribution strategies listed in Table 1

Figure 7 shows the simulated cooling rate $(R)$ distribution along CPC1 under different mold temperature distributions. The HT-475 and LLT-550 cases are the critical conditions without hot tearing (Fig. 6), and the LLT-475 and GT-550 cases with hot tearing are used for comparison. Generally, the cooling rate peaks at the constrained end and gradually decreases from the constrained end to the sprue, indicating typical progressive solidification from the constrained end to the sprue.

The cooling rates of HT-475 and LLT-475 are consistent with each other from Nodes 1 to 7 , while the cooling rates of LLT-475 from Nodes 8 to 10 were obviously higher than those of HT-475 (positions of the nodes are shown in Fig. 3). The higher cooling rate from Nodes 8 to 10 of LLT-475 case is due to the chilling effect of cover plate $\mathrm{C}$ [(Fig. 1(d)], the temperature of which was only about $25{ }^{\circ} \mathrm{C}$ when CPC1 was cast. The only difference between HT-475 and LLT-475 is the mold temperature of cover plate $\mathrm{C}$, therefore, the chilling effect of cover plate $\mathrm{C}$ in LLT-475 causes hot tearing. To eliminate hot tearing of LLT-475, the mold temperature has to be raised $75{ }^{\circ} \mathrm{C}$ higher (LLT-550) when cover plate $\mathrm{C}$ (a chiller) is added. Therefore, under the progressive solidification of the present study, adding a chiller is useless in reducing hot tearing; instead, it increased the HTS of CPC1.

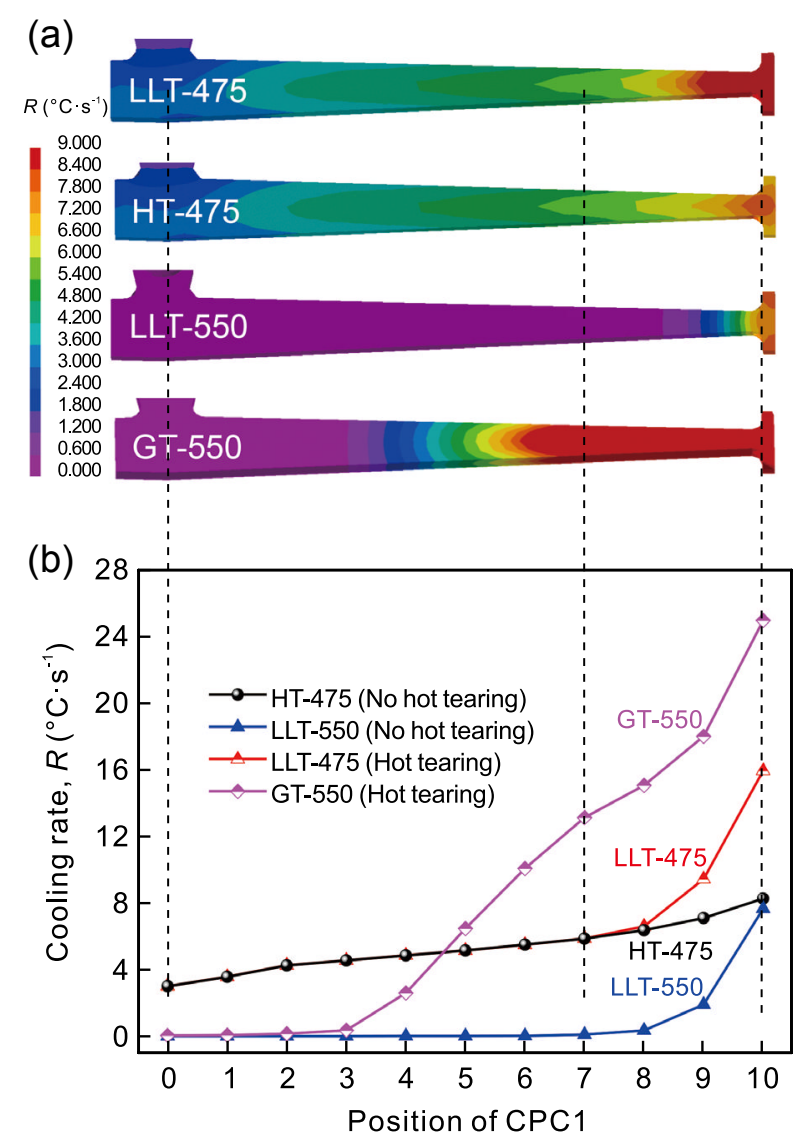

Fig. 7: Simulated cooling rate distributions along CPC1 under HT, LLT, GT distributions: (a) cloud images of calculated cooling rates; (b) calculated cooling rates along CPC1 from sprue to constraint end, where position number corresponds to node number in Fig. 3(a)

Comparing the cooling rate distribution of HT-475 with that of LLT-550, it is apparent that the cooling rates of the latter are much lower with the exception of Node 10. As the temperature required to avoid hot tearing under the HT distribution $\left(475^{\circ} \mathrm{C}\right)$ is lower than that of the LLT distribution $\left(550{ }^{\circ} \mathrm{C}\right)$, the former is a better choice to eliminate hot tearing.

Among the cooling rate distributions of HT-475, LLT-475, LLT-550, and GT-550, it is apparent that the cooling rate variation range of GT-550 is the widest, followed by LLT-475 and LLT-550, and that of the HT-475 is the narrowest. The variation in the range of cooling rates from the constraint end 
to the sprue indicates the extent of progressive solidification. Therefore, the GT distribution generates the highest extent of progressive solidification from the constraint end to the sprue, followed by the LLT distribution and then the HT distribution.

Figure 8 shows the calculated cooling rates of CPC1 from the sprue to the constraint end, where the position number corresponds to the node number in Fig. 3(a). It is apparent that the maximum cooling rates are closely related to the appearance of hot tearing. All cases with hot tearing have higher maximum cooling rates at the constrained end (Node 10) than those without hot tearing. There appears to be a critical cooling rate beyond which hot tearing appears. For the constrained plate casting with a constraint length of $300 \mathrm{~mm}$ (CPC1), the critical cooling rate is about $8.3^{\circ} \mathrm{C} \cdot \mathrm{s}^{-1}$. Therefore, under progressive solidification conditions, the maximum cooling rate at the constrained end is probably one of the key factors to determine whether hot tearing appears.

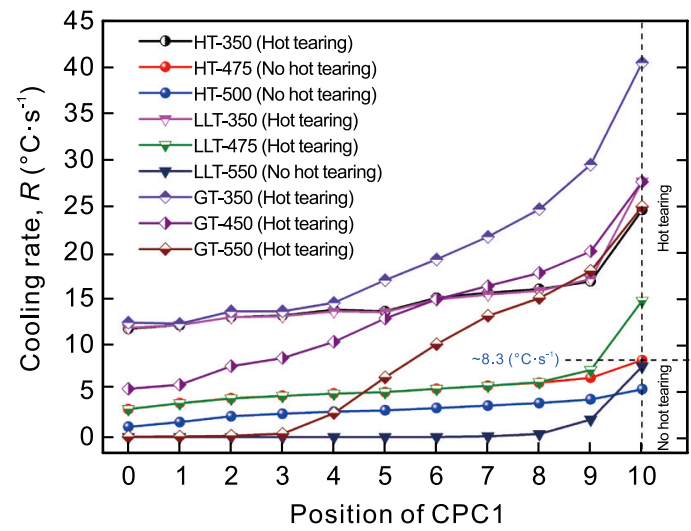

Fig. 8: Calculated cooling rates along CPC1 from sprue to constraint end

\subsection{Effect of constraint and constraint length}

Figure 9 presents representative images of CPC2 and CPC3 under the HT distribution. In $\mathrm{CPC} 2$, at a very low initial mold temperature of $150{ }^{\circ} \mathrm{C}$, hot tearing appears in the longer constrained plate; no hot tearing appears in the shorter constrained plate. In CPC3, when the constrained ends are removed, even for plates of up to $285 \mathrm{~mm}$ in length, no hot tearing is observed at a very low initial mold temperature of $150^{\circ} \mathrm{C}$.

Figure 10 shows the appearance of hot tearing in $\mathrm{CPC} 1$, $\mathrm{CPC} 2$, and $\mathrm{CPC} 3$ under the HT distribution. It is apparent that, without the constrained end (CPC3), no hot tearing appears. In $\mathrm{CPC} 2$, no hot tearing appears even at a low mold temperature as low as $100{ }^{\circ} \mathrm{C}$ in the short constrained plate (CPC2-short), while for the long constrained plate (CPC2-long), hot tearing disappears when the mold temperature is $275^{\circ} \mathrm{C}$ or higher. When the constraint length increases to $300 \mathrm{~mm}$ (CPC1), a much higher temperature of $475{ }^{\circ} \mathrm{C}$ is required to eliminate hot tearing. Such experimental evidence confirms that the constraint and constraint length are the important factors in determining the occurrence of hot tearing.

The calculated cooling rates of the longer constraint plate of $\mathrm{CPC} 2$ from the sprue to the constraint end are shown in Fig. 11, and the position number corresponds to the node number in Fig. 3(b). It is found that the critical cooling rate is about $25.5^{\circ} \mathrm{C} \cdot \mathrm{s}^{-1}$, below which hot tearing does not occur. By comparing Figs. 8 and 11, it can be concluded that the constraint length is an important factor that induces hot tearing during the progressive solidification process, with a longer constraint length corresponding to a lower critical cooling rate.

(a)
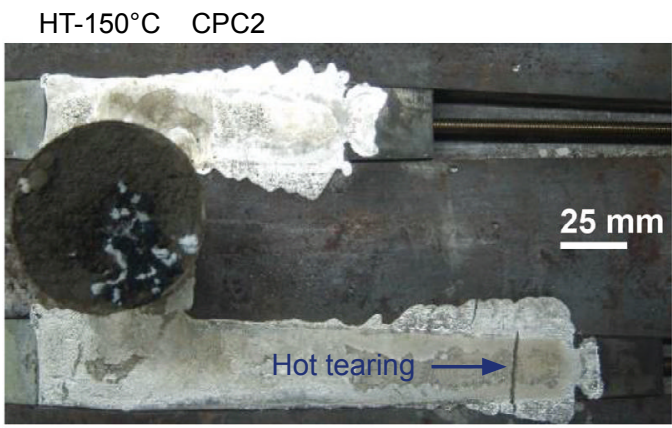

(b)

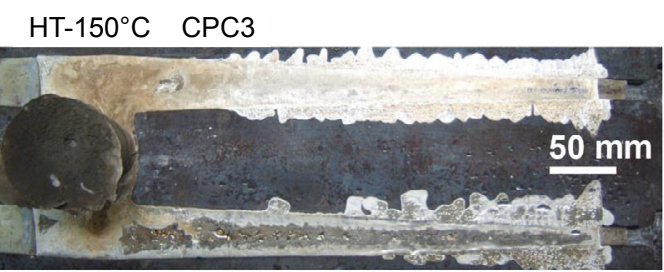

Fig. 9: Representative images of CPC2 (a) and CPC3 (b) at initial mold temperature of $150{ }^{\circ} \mathrm{C}$ under HT distribution

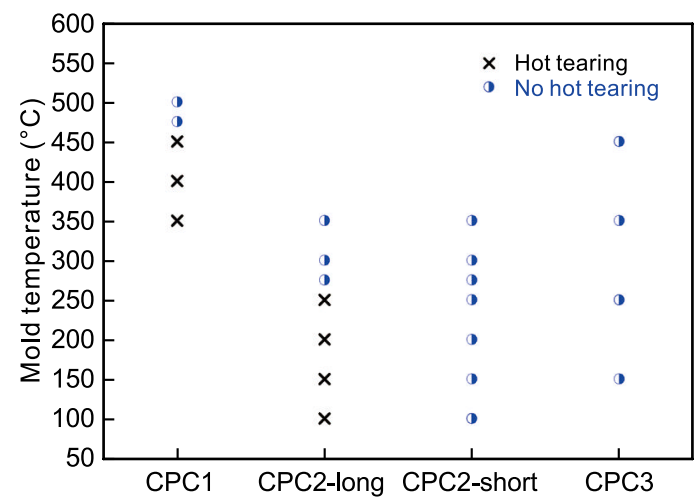

Fig. 10: Appearances of hot tearing of CPC1, CPC2, and CPC3 under HT distribution listed in Table 1, CPC2-long and $\mathrm{CPC} 2$-short stand for long and short constraint plates of CPC2, respectively

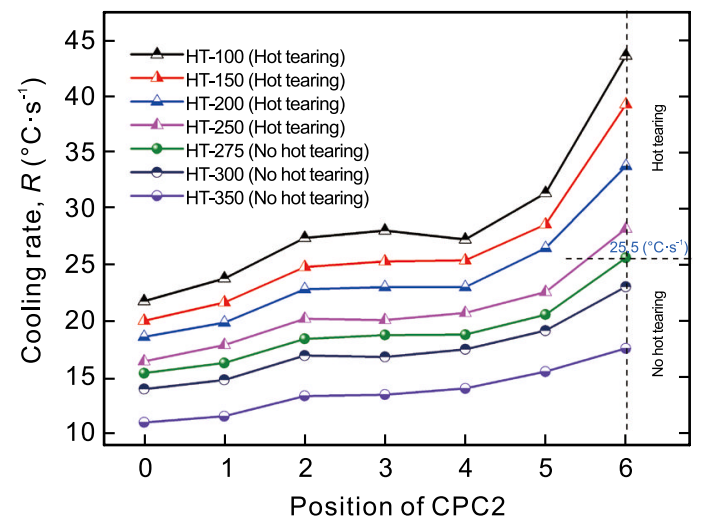

Fig. 11: Calculated cooling rates of the longer constraint plate of CPC2 from sprue to constraint end 


\section{Discussion}

\subsection{Determining factors for hot tearing}

The above results suggest that the maximum cooling rate under progressive solidification (Figs. 8 and 11) and the constraint length (Figs. 9 and 10) are two key factors that determine the generation of hot tearing and can thus be considered as the determinant factors of hot tearing whether can occur. Decreasing the maximum cooling rate and constraint length help to reduce the tendency for hot tearing.

Stress is generally generated by the restriction of solidification shrinkage and thermal contraction, and strain is formed at the weak point of the component ${ }^{[2]}$. The weak points are generally those of later-solidifying regions, because the strength of an alloy decreases with increasing temperature in the semisolid stage ${ }^{[2,10]}$. These strains can be accommodated by plastic deformation, diffusion-aided creep, structure rearrangement, and filling of the gaps and pores with the liquid, all of which require time ${ }^{[23]}$. If the strain rates are sufficient high, there is insufficient time for the strains to be accommodated by the above processes and hot tearing occurs ${ }^{[24,25,26]}$. If the strain is concentrated in a small area, we simplify the analysis here as a unit volume, and the strain rate in the small area during solidification can be simply calculated as:

$$
\varepsilon=V \cdot k_{1-2} / \Delta t
$$

where $\varepsilon$ is the strain rate, $V$ is the volume of liquid metal, $k_{1-2}$ is the shrinkage rate from $T_{1}$ to $T_{2}$, and $\Delta t$ is the cooling time from $T_{1}$ to $T_{2}$. For the temperature range $\left(T_{1}-T_{2}\right), k_{1-2}$ can be considered as a constant for an alloy with known chemical composition. For ease of understanding, $T_{1}$ and $T_{2}$ can be treated as temperatures of $623{ }^{\circ} \mathrm{C}$ and $529{ }^{\circ} \mathrm{C}$ (corresponding to solid fractions $f_{\mathrm{s}}=0.74$ and 1 ) for the NZ30K alloy in this study, respectively. Therefore, if the strain is concentrated in a unit volume, the strain rate $\varepsilon$ is determined by the volume $V$ and cooling time $\Delta t$. The volume $V$ in the present study can be treated as the volume of the plate and $\Delta t$ is determined by the cooling rate $(R)$. For a higher $R, \Delta t$ is shorter and $\varepsilon$ is higher, which is more likely to initiate hot tearing. $V$ and $R$ for determining the strain rate in Eq. (1) correspond to the two determining factors for hot tearing identified in this study: the constraint length and maximum cooling rate. A greater constraint length corresponds to a larger volume of liquid metal $V$ and a higher maximum cooling rate indicates a higher cooling rate. Therefore, the reduction of the constraint length or maximum cooling rate can decrease the strain rate, which facilitates other processes (such as plastic deformation, diffusion-aided creep, structure rearrangement, and filling of the gaps and pores with the liquid) to accommodate the strains, thereby increasing the hot tearing resistance.

\subsection{Progressive solidification and hot tearing}

Results from Section 3 show that the HT distribution is determined as the best option to avoid hot tearing, followed by the LLT distribution (with a chiller), and finally the GT distribution. Such behavior could be explained as follows: based on Eq. (1), the strain rate is generally determined by the volume of liquid metal $V$ and the cooling time $\Delta t$. The volume of liquid metal $V$ of $\mathrm{CPC} 1$ is constant in the present study. Therefore, the strain rate of $\mathrm{CPC} 1$ during solidification is only determined by the cooling time $\Delta t$, which is further determined by the cooling rate $(R)$. As shown in Fig. 7, comparing the cooling rate distributions of HT-475 and LLT-475, it is clear that adding a chiller leads to a significant increase of the cooling rate from Node 9 to Node 10 (the constraint end); therefore, it can be expected that the strain rate of LLT-475 during solidification is higher than that of HT-475, which makes it easier to initiate hot tearing in LLT-475. Therefore, compared with the HT distribution, adding a chiller (LLT) results in a higher cooling rate, which leads to a higher strain rate during solidification and makes hot tearing more likely to initiate.

Similarly, comparing the cooling rate distributions of GT550 and LLT-550 in Fig. 7, it is apparent that the cooling rates of GT-550 are much higher. According to Eq. (1), the strain rate of GT-550 during solidification should be much higher than that of LLT-550, which increases the HTS of GT550. Therefore, compared with the LLT distribution, the GT distribution leads to even higher cooling rates and is more prone to initiate hot tearing.

All three temperature distributions investigated in this study provid progressive solidification from the constrained end to the sprue, some of which initiate hot tearing and others not. Progressive solidification is therefore not a sufficient and necessary condition to avoid the formation of hot tearing. Progressive solidification alone cannot guarantee a low enough cooling rate or strain rate that can eliminate hot tearing; therefore, progressive solidification alone cannot solve the problem of hot tearing. The two determining factors for hot tearing are the maximum cooling rate at the constraint end under progressive solidification and the constraint length. When these two parameters are reduced to a certain value, no hot tearing initiates.

\section{Conclusions}

New constrained plate castings (CPCs) with progressive changes in cross-section were designed to enable progressive solidification. The hot tearing behaviors of a newly developed NZ30K Mg alloy (Mg-3.0Nd-0.2Zn-Zr, wt.\%) were studied under progressive solidification using various mold temperature, mold temperature distribution strategies and constraint lengths. The following conclusions can be drawn:

(1) During progressive solidification of the castings under constrained contraction, the mold temperature must be set to a high enough temperature to avoid hot tearing of $\mathrm{NZ30K} \mathrm{Mg}$ alloy. The hot tearing of CPC1 only disappears when the mold temperature reaches $475{ }^{\circ} \mathrm{C}$ or higher under a homogeneous mold temperature distribution. 
(2) Of the three different mold temperature distributions examined, a homogeneous mold temperature distribution is the best option to avoid hot tearing, followed by a local low mold temperature distribution (with a chiller), and finally a gradient mold temperature distribution. Compared with the homogeneous mold temperature distribution, a higher mold temperature is required to avoid hot tearing when a chiller is added.

(3) A constraint is a necessary condition for initiating hot tearing. When there is no constraint (i.e., the constrained ends are removed in $\mathrm{CPC} 3$ ), hot tearing does not occur. When there is constraint (CPC2), the decrease of the constraint length increases the hot tearing resistant.

(4) Progressive solidification is not a sufficient and necessary condition to avoid the formation of hot tearing. The two key factors determining the hot tearing of $\mathrm{Mg}$ alloy under constrained contraction during progressive solidification are the maximum cooling rate at the constrained end and the constraint length. Decreasing their values can reduce the occurrence of hot tearing.

\section{Acknowledgements}

This research work was supported by the National Key Research and Development Program of China (Grant Nos.: 2016 YFB0701204 and 2016YFB0301002), the National Natural Science Foundation of China (Grant Nos.: 51671128, 51771113, and 51821001), and the Shanghai Rising-Star Program (Grant No.: 15QB1402700).

\section{References}

[1] Luo A A. Magnesium casting technology for structural applications. J. Magnes. Alloy., 2013, 1(1): 2-22.

[2] Pan $F$, Yang $M$, Chen $X$. A review on casting magnesium alloys: Modification of commercial alloys and development of new alloys. J. Mater. Sci. Technol., 2016, 32(12): 1211-1221.

[3] Wang Z, Song J F, Huang $Y$ D, et al. An investigation on hot tearing of $\mathrm{Mg}-4.5 \mathrm{Zn}-(0.5 \mathrm{Zr})$ alloys with $\mathrm{Y}$ additions. Metall. Mater. Trans. A, 2015, 46(5): 2108-2118.

[4] Cao G, Kou S. Hot cracking of binary Mg-Al alloy castings. Mater. Sci. Eng., 2006, A417(1-2): 230-238.

[5] Zhou L, Huang Y D, Mao P L, et al. Influence of composition on hot tearing in binary Mg-Zn alloys. Int. J. Cast Metal Res., 2011, 24(3-4): 170-176.

[6] Song J F, Wang Z, Huang Y D, et al. Hot tearing susceptibility of Mg-Ca binary alloys. Metall. Mater. Trans. A, 2015, 46(12): 6003-6017.

[7] Easton M A, Gibson M A, Zhu S M, et al. An a priori hot-tearing indicator applied to die-cast magnesium-rare earth alloys. Metall. Mater. Trans. A, 2014, 45(8): 3586-3595.
[8] Zhou L. Investigations on hot tearing susceptibility and mechanism for Mg-Zn-(Al) alloys. Ph.D. Thesis. China: Shenyang University of Technology, 2011. (In Chinese)

[9] Yang Z Z, Wang K, Fu P H, et al. Influence of alloying elements on hot tearing susceptibility of $\mathrm{Mg}-\mathrm{Zn}$ alloys based on thermodynamic calculation and experimental. J. Magnes. Alloy., 2018, 6(1): 44-51.

[10] Cao G, Kou S. Hot tearing of ternary Mg-Al-Ca alloy castings. Metall. Mater. Trans. A, 2006, 37(12): 3647-3663.

[11] Cao G, Haygood I, Kou S. Onset of hot tearing in ternary MgAl-Sr alloy castings. Metall. Mater. Trans. A, 2010, 41(8): 2139-2150.

[12] Song J F, Wang Z, Huang $Y D$, et al. Hot tearing characteristics of Mg-2Ca-xZn alloys. J. Mater. Sci., 2016, 51(5): 2687-2704.

[13] Huang $H$, Fu P H, Wang $Y X$, et al. Effect of pouring and mold temperatures on hot tearing susceptibility of AZ91D and Mg$3 \mathrm{Nd}-0.2 \mathrm{Zn}-\mathrm{Zr} \mathrm{Mg}$ alloys. Trans. Nonferrous Met. Soc., 2014, 24: 922-929.

[14] Kotas P, Tutum C C, Thorborg J, et al. Elimination of hot tears in steel castings by means of solidification pattern optimization. Metall. Mater. Trans. B, 2012, 43(3): 609-626.

[15] Fu P H, Peng L M, Jang $H$ Y, et al. Effects of heat treatments on the microstructures and mechanical properties of $\mathrm{Mg}-3 \mathrm{Nd}$ $0.2 Z n-0.4 Z$ r (wt.\%) alloy. Mater. Sci. Eng. A, 2008, 486(1-2): 183-192.

[16] Fu P H, Peng L M, Jang H Y, et al. Chemical composition optimization of gravity cast $\mathrm{Mg}-y \mathrm{Nd}-x \mathrm{Zn}-\mathrm{Zr}$ alloy. Mater. Sci. Eng. A, 2008, 496(1-2): 177-188.

[17] Li Z M, Wang Q G, Luo A A, et al. High cycle fatigue of cast Mg-3Nd-0.2Zn magnesium alloys. Metall. Mater. Trans. A, 2013, 44(11): 5202-5215.

[18] Li Z M, Luo A A, Wang Q G, et al. Fatigue properties of cast magnesium wheels. Metall. Mater. Trans. A, 2016, 47(8): 4239-4257.

[19] Gunde P, Schiffl A, Uggowitzer P J. Influence of yttrium additions on the hot tearing susceptibility of magnesium-zinc alloys. Mater. Sci. Eng. A, 2010, 527(26): 7074-7079.

[20] Li S S, Tang B, Jin X Y, et al. An investigation on hot-cracking mechanism of $\mathrm{Sr}$ addition into Mg-6Al-0.5Mn alloy. J. Mater. Sci., 2012, 47(4): 2000-2004.

[21] ESI Group Inc: ProCAST 2010.0 User Manual. 2010.

[22] Dahle A K, Stjohn D H. Rheological behaviour of the mushy zone and its effect on the formation of casting defects during solidification. Acta Mater., 1998, 47(1): 31-41.

[23] Eskin D G, Katgerman L. A quest for a new hot tearing criterion. Metall. Mater. Trans. A, 2007, 38(7): 1511-1519.

[24] Eskin D G, Suyitno, Katgerman L. Mechanical properties in the semi-solid state and hot tearing of aluminium alloys. Prog. Mater. Sci., 2004, 49(5): 629-711.

[25] Rappaz M, Drezet J M, Gremaud M. A new hot-tearing criterion. Metall. Mater. Trans. A, 1999, 30(2): 449-455.

[26] Fabrégue D, Deschamps A, Suery $M$, et al. Non-isothermal tensile tests during solidification of $\mathrm{Al}-\mathrm{Mg}-\mathrm{Si}-\mathrm{Cu}$ alloys: Mechanical properties in relation to the phenomenon of hot tearing. Acta Mater., 2006, 54(19): 5209-5220. 